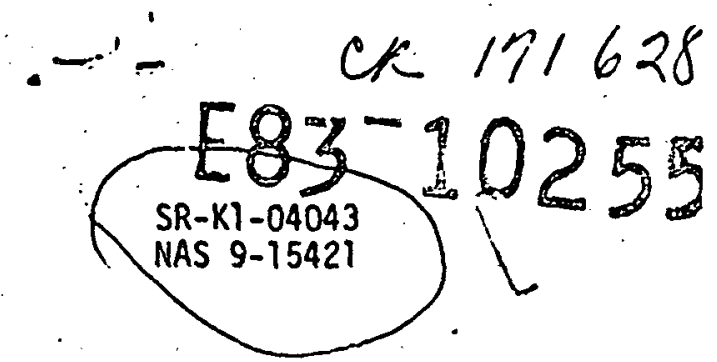

A Joint Program for Agriculture and Resources Inventory Sunveys Through Aerospace Remote Sensing

\title{
Supporting Research
}

February 1981

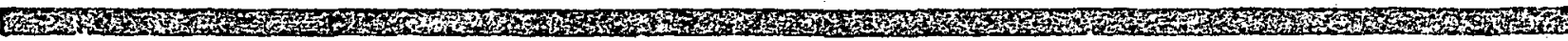

\section{CROP CLASSIFICATION USING AIRBORNE RADAR AND LANDSAT DATA}

F. T. Ulaby, R. Y. Li and K. S. Shanmugam

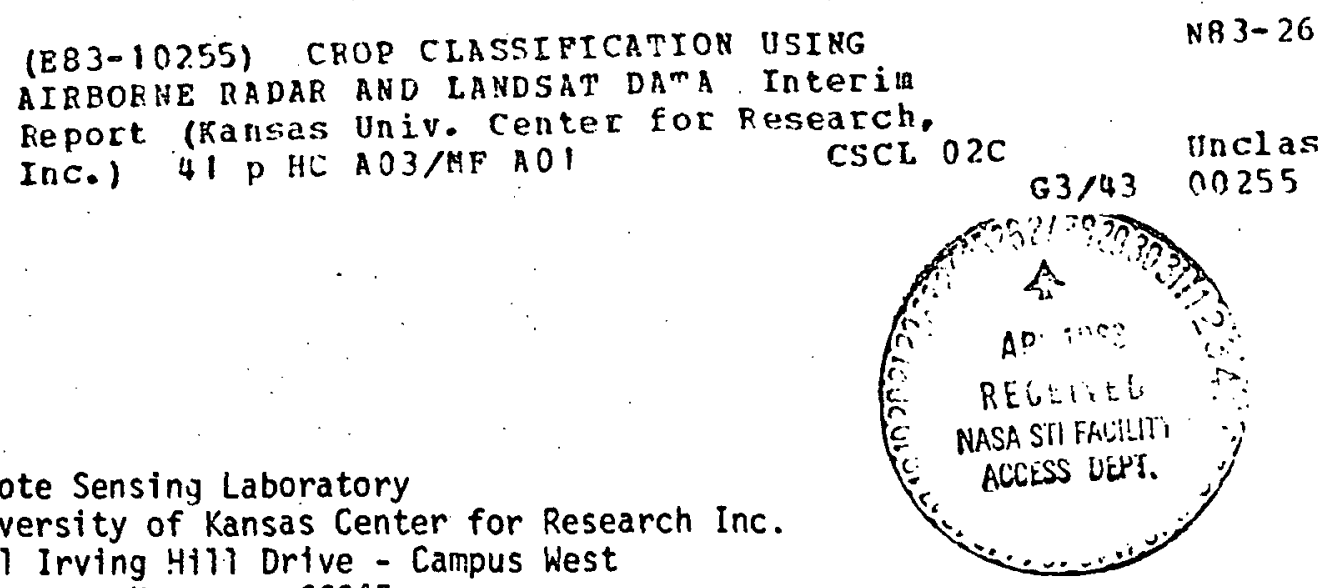

Remote Sensing Laboratory University of Kansas Center for Research Inc. 2291 Irving 4111 Drive - Campus West Lawrence, Kansas 66045
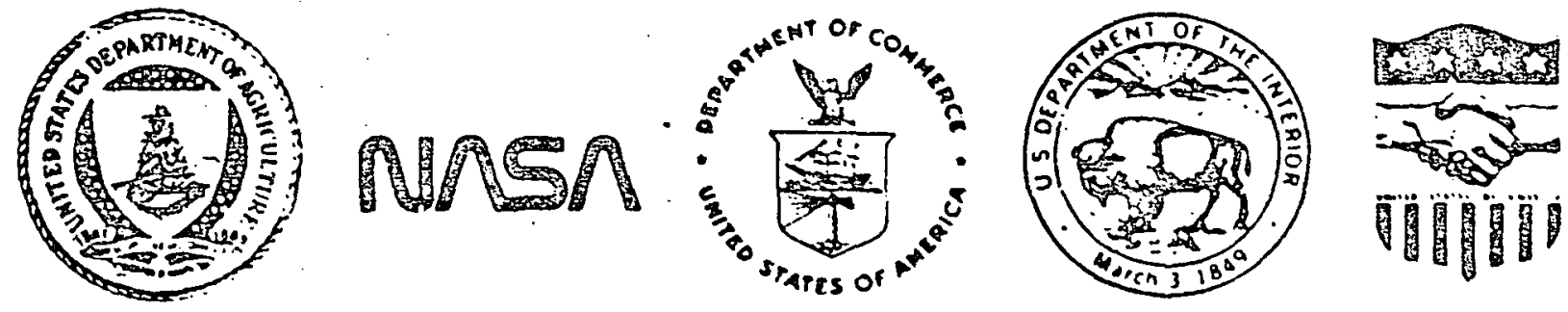

Lyindon B. Johnson Space Center Housion. Texas?7058 


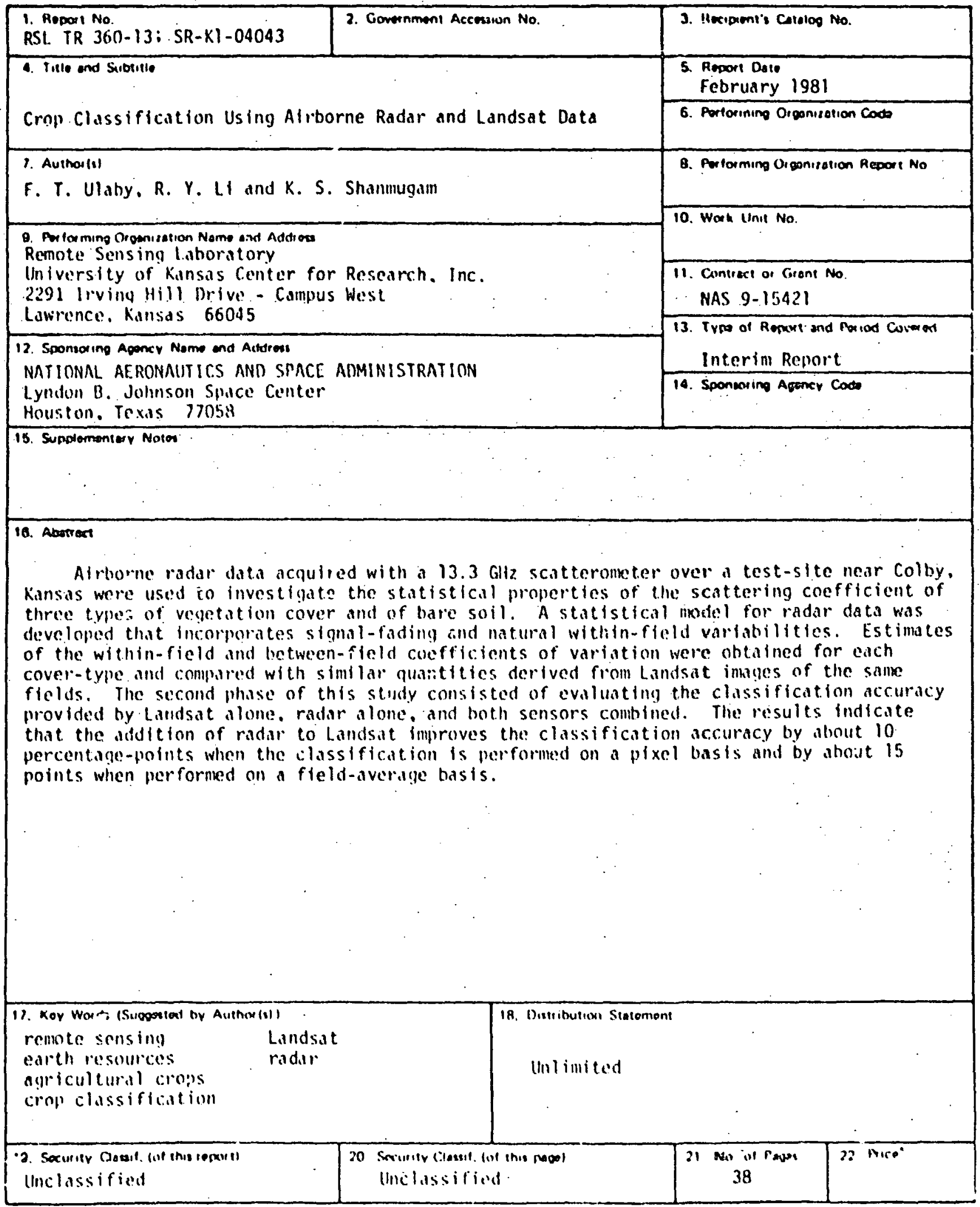

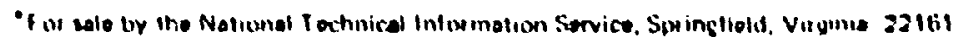




\section{THE UNIVERSITY OF KANSAS CENTER FOR RESEARCH, INC.}

2291 Irving Hill Drive-Compus West

Lowrence, Konsos 66045

Tolophuno: (913) $864-4832$

\section{CROP CLASSIFICATION USING AIRBORNE RADAR}

AND LANDSAT DATA

Remote Sensing Laboratory

RSL Technical Report 360-13

F. T. Ulaby

R. Y. Li

K. S. Shanmugam

February 1981

Fanaz T. Ulaby, Principal Investigator

Supported by:

NATIONAL AERONAUTICS AND SPACE ADMINISTRATION

Lyndon B. Johnson Space Center

Houston. Texas 7705.9

CONTRACT NAS 9-15421 


\section{TABLE OF CONTENTS}

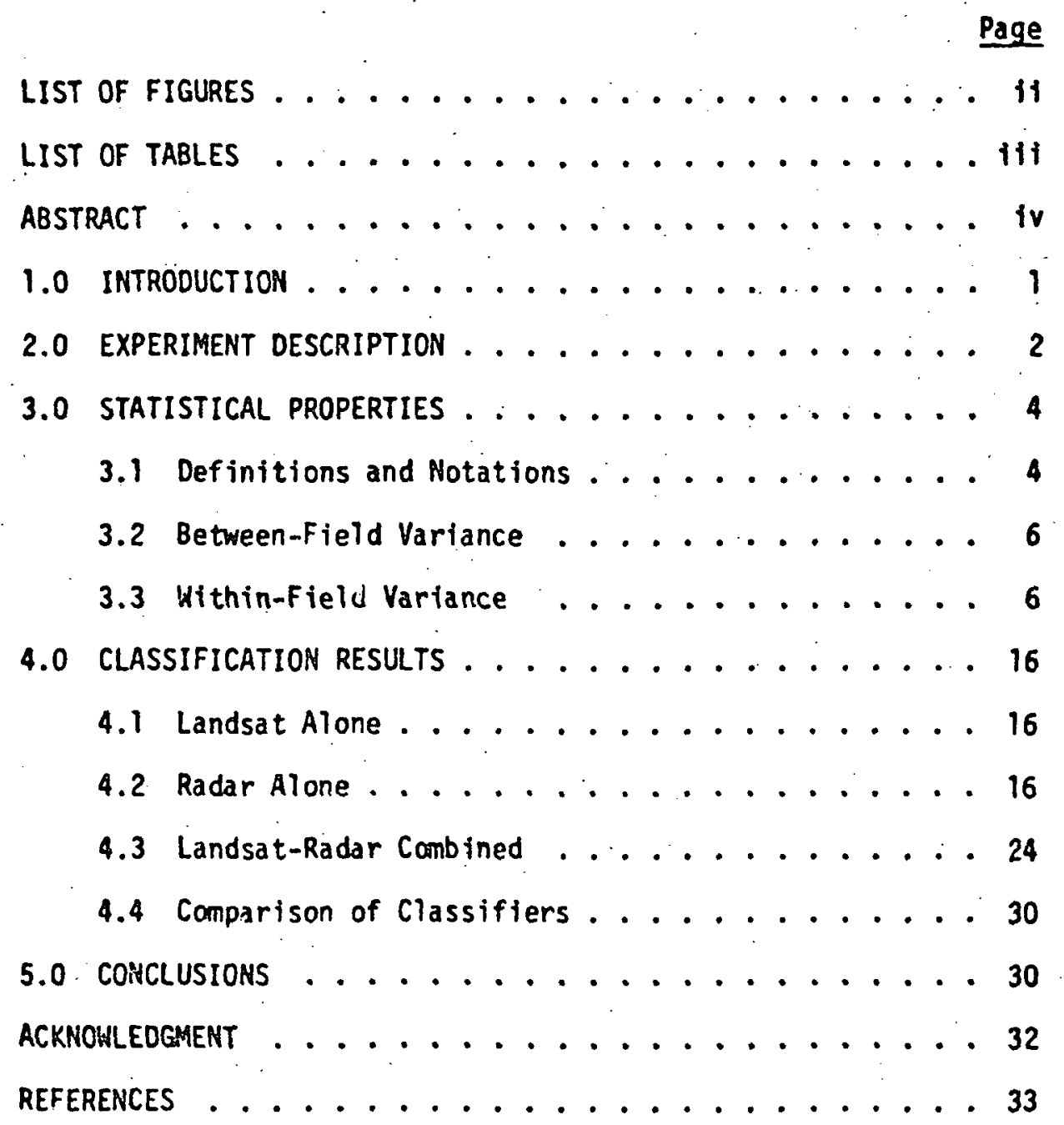




\section{ORIGINAL PAGE IS \\ OF POOR QUALITY}

\section{LIST OF FIGURES}

Page

Figure 1 Plots of the probabflity density function $f\left(Z_{N}^{i}\right)$ for $(a) N=16$, and $(b) N=64 \ldots . . . .11$

Figure 2 Plot of ${ }^{2} Z_{N}^{\prime}$ as a function of the number of the

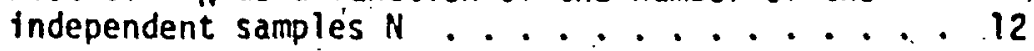

Figure 3 llistogram of $S^{\prime}(d B)$ for wheat stubble on $7 / 18 / 78$. 17

Figure 4 Histogram of $S^{\prime}(d B)$ for corn on $7 / 18 / 78$. . . 18

Figure 5 Histogram of $S^{\prime}(d B)$ for bare soil on $7 / 18 / 78 \ldots 19$

Figure 6 Classification results using four Landsat channels from the 1978 Colby data......... 20

Figure 7 Distributions of field averages of agricultural fields for both July 18 (before rain) and July 20 (after rain) radar data. Upper and lower bounds are maximum and minimumi values of $\mu$ ir and the inbetween level is the average value ir...... 23

Figure 8 Radar classification performance using measured pixeis, $S^{\prime}(d B)$, for the $7 / 18 / 78$ and $7 / 20 ; 78$

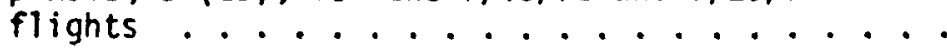

Figure 9 Comparison of classification accuracies obtained for classification applied on a pixel (cell) basis and on a field-average basis . . . . . 27

Figure 10 Combined Landsat/radar classification based on 1978 Colby data . . . . . . . . . 28

Figure $i 1$ Combined Landsat/radar classification accuracy on a field-average basis. Entries are the number of fields................ 29

Figure 12 Compariscn of classification performance of different classifiers for the combined Landsat/radar data set................... 31 


\section{LIST OF TABLES}

Page

Table 1 Distribution of Fields Among Cover Categories . . 3

Table 2 Iverage Wtthin-Field and Between-Field Coefficients of Variation ............. 7

Table 3 Relative Contributions of Fading (with $N=69$ ) and Spatial Variances to the Total Within-Field Variance of $\mathrm{S}^{\prime}$ (Scattering Coefficient in $\mathrm{dB}$ ) ...... 13

Table 4 Comparison of Total Standard Deviation â. Incorporating Fading. Within-Field and Between-Field

Variations............ 15

Table 5 Crop Confusion Tables for (a) Landsat Alone, (b) Radar Alone, and (c) Both Combined....... 21

Table 6 Crop Confusion Tables for Radar Flights of $7 / 18 / 78$ and $7 / 20 / 78$ (Before and After Rain) .... 26 


\title{
ORIGINAL PAGE IS \\ OF POOR QUALITY
}

\section{CROP CLASSIFICATION USING AIRBORNE RADAR AND LANDSAT DATA}

\author{
F. T. Ulaby, R. Y. LI and K. S. Shanmugam \\ Remote Sensing Laboratory \\ University of Kansas Center for Research, Inc. \\ Lawrence, Kansas 66045.
}

\section{ABSTRACT}

Airborne radar data acquired with a $13.3 \mathrm{GHz}$ scatterometer over a test-site near Colby, Kansas were used to investigate the statistical properties of the scattering coefficient of three types of vegetation cover and of bare soil. A statistical model for radar. data deve?oped that incorporates signal-fading and natural within-field variabilities. Estimates of the within-field and between-field coefficients of variation were obtained for each cover-type and compared with similar quantities derived from Landsat Images of the same fields. The second phase of this study consisted of evaluating the classification accuracy provided by Landsat alone, radar alone, and both sensors combined. The results indicate that the addition of radar to Landsat improves the classification accuracy by about 10 percentage-points when the classification is performed on a pixel tasis and by about 15 points when performed on a field-average basis. 


\subsection{INTRODUCTION}

Over the past several years, Landsat's Multispectral Scanners (MSS) have provided a continuous stream of multitemporal images for a large portion of the earth's surface. The availability of such a data-source has led to numerous investigations of the crop-classification capabilities and limitations of optical sensors. One of the major conclusions of these studies is that, in order to achieve high correct-classification rates, it is necessary to have uninterrupted (cloud-free) coverage of the area under investigation for successive passes. One way to rectify this interruption problem is to use radar, which effectively is imune to the presence of clouds in the atmosphere. If used in conjunction with optical sensors, radar can, potentially: (a) improve the cropclassification rates under clear-sky conditions tecause it responds to the geometrical and dielectric properties of vegetation [1-4] differently than do optical sensors, and (b) serve as a "substitute". for optical senscrs during cloud-cover conditions.

Several crop-classification studies have been conducted using single- and/or two-date radar imagery [5-9], but no investigations have yet been reported in which periodic, repetitive coverage with imaging radar over the full growing-season has been employed. The first attempt to evaluate the significance of multitemporal radar observations was made by simulating radar imagery based on data acquired by a truckmounted radar system [4] and by incorporating system parameters (resolution, signal-fading, etc.) and target parameters (slope, within-and between-field variance) in the simulation procedure. However, a simulated image is inherentiy limited by the assumptions and statistical distributions used in its generation. The above study was extended a step further by evaluating the combined Landsat/radar multitemporal crop classification wherein the iadar data consisted of simulated images of the same scene abserved by Landsat's MSS [10]. Again, the basic source of radar data was a truck-mounted radar. Similar studies also were conducted in Canada using single-date data acquired by airborne optical and radar scatterometer systems [11]. 
ORIGINAL PAGE IS

OF POOR QUALTY

In 1978, sevenmisstons were flown by NASA/Johnson Space Center's C-130 aircraft over an agricultural test-site near Colby, Kansas in support of a soll-moisture investigation. Among the hist of sensors used was a $13.3 \mathrm{GHz}$ radar scatterometer (non-imaging). To date, the data acquired in the first two flights have been processed by NASA/JSC and made available for analysis. These data are used in the present study to: (a) investigate the statistical nature of the radar backscattering coefficient for bare ground and for three difierent croptypes, including within-field and between-field variations, and (b) evaluate the crop-classification rates obtained using Landsat alone, radar alone, and both combined.

\subsection{EXPERIMENT DESCRIPTION}

The test site used for this investigation is located near colby, Kansas, in the northwestern part of the state. The available radardata consist of backscatter measurements for seven flight-lines, acquired by the NASA/JSC $13.3 \mathrm{GHz}$ scatterometer from an altitude of $460 \mathrm{~m}$ above the ground. The scatterometer is a fan-beam Doppler system, VV polarized, and has a $2.5^{\circ}$ beanwidth in the cross-track direction. The Ooppler spectrum was processed to yield a $37-m$ resolution in the along-track direction. Although the scatterometer was used to measure the backscattering coefficient at several angles of incidence (relative to nadir) between $5^{\circ}$ and $60^{\circ}$, only the $50^{\circ}$ data are used in this study in order to minimize the effects of soil moisture variations on crop identification. For $\theta=50^{\circ}$, the resolution-cell size is $37 \mathrm{~m} \times 31 \mathrm{~m}$. As the aircraft bearing the scatterometer flew across, the scatterometer measured the return from 10 contiguous cells within each field, with the field-size being approximately $400 \mathrm{~m} \times 400 \mathrm{~m}$. In this study, the analysis is based on daca for 36 fields (Table 1), for which detailed ground-truth information is available and which appear spatially "homogeneous" on aerial photography. Ground observations include croptype and height, row spacing, soil moisture content and regetation moisture car :ent (for a limited number of fields).

Because of the coherent nature of the transmitted signal, the backscattered energy measured by a radar system exhibits random 


\section{ORIGINAL PAGE IS \\ OF POOR QUALITY}

TABLE 1

Distribution of Fields Among Cover Categories

\begin{tabular}{|l|c|}
\hline \multicolumn{1}{|c|}{ Cover } & $\begin{array}{c}\text { Number of Ftelds } \\
\text { (Each } 400 \mathrm{~m} \times 400 \mathrm{~m})\end{array}$ \\
\hline Wheat Stubble & 12 \\
\hline Corn & 11 \\
\hline Fallow (Bare Soil) & 10 \\
\hline Pasture (Short Grass) & 3 \\
\hline
\end{tabular}


fiuctuating component of the received signal, spatial and/or frequency averaging usually is used. For a given set of radar and flight parameters, the number of independent samples, N, incorporated in the measurement of the power backscattered from a given ground cell is determined easily through readily available expressions; in the case of the Doppler scatterometer used for this investigation, $N=69$ for each $37 \mathrm{~m} \times 31 \mathrm{~m}$ cell [12]. Assuming Rayleigh statistics [13], the received power is described by a Chi-square distribution with $2 \mathrm{~N}$ degrees of freedm, whose mean, $S$, (for a given cell) is related to the variance $\sigma^{2}$ of the distribution through

$$
\frac{\sigma^{2}}{S^{2}}=\frac{1}{N}
$$

For $N$ larger than about 20 , the Chi-square distribution approaches a truncated nomal distribution, which is a valid approximation in the present case $(N=69)$. This information will be used in the next section for evaluating the within-field variance due to differences in the scat- tering properties of different cells within the same field (over and above the variance due to fading).

\subsection{STATISTICAL PROPERTIES}

The next section is concerned with the application of classification techniques using the available radar data and Landsat MSS data for the same fields. The Landsat images were recorded on 26 July 1978, approximately a week after the July 18 and 20,1978 , radar +1 ights. The statistical properties of the radar and optical data are discussed in this section, as a precursor to the classification task (next section).

\subsection{Definitions and Notations}

The 36 available fields are distributed among four categories: wheat stubble, corn, fallow (bare ground), and pasture (grass), with an approximately even distribution among the first three (Table 1) and only three fields of dasture Fan man ... 


\section{ORIGINRL PAGE IS OF POOR QUALTT}

$I_{i f}=$ Landsat image tonal value (for a given band) of the $f^{\text {th }}$ pixel of the $f^{\text {th }}$ field

$S_{i j}=$ measured radar scattering coefficient of the $j^{\text {th }}$ pixel of the $i^{\text {th }}$ field

$N_{f}=$ number of fields (for the category under consideration)

$N_{c l}=$ number of Landsat cells (pixels) per field $=30$

$N_{c r}=$ number of radar cells per field $=10$

$N=$ number of independent samp? es incorpcrated in the measurement of $S_{i j} ; N=69$ in this case

$\mu_{i \ell}=$ mean Landsat image value for field $i=E_{j}\left(I_{i j}\right)$

$\hat{\mu}_{i \ell}=\frac{1}{N_{c \ell}} \sum_{j=1}^{N_{c \ell}} I_{i j}$

$\mu_{\text {ir }}=$ mean radar scattering coefficient values for field $i=E_{j}\left(S_{i j}\right)$

$\dot{u}_{i r}=\frac{1}{N_{c r}} \sum_{j=1}^{N_{c r}} s_{i j}$.

$u_{\ell}=E_{i}\left(u_{i \ell}\right)$ Population means for all cells of

$u_{r}=E_{i}\left(u_{i r}\right)$ all fields of the category under consideration 


\subsection{Between-Field Variance}

The hetween-fielc variance for a given category is given by:

$$
\sigma_{B F_{\ell}}^{2}=E_{j}\left(\mu_{i \ell}^{2}\right)-\mu_{l}^{2} \quad \text {, for Landsat }
$$

and

$$
\sigma_{B F r}^{2}=E_{i}\left(\mu_{i r}^{2}\right)-\mu_{r}^{2} \quad \text {, for radar }
$$

Table 2 shows estimated values of the coefficients of variation, $\hat{C}_{B F e}=$ $\hat{\sigma}_{B F \ell} / \hat{\mu}_{\ell}$ for Landsat and $\hat{C}_{B F r}=\hat{\sigma}_{B F r} / \hat{\mu}_{r}$ for radar, for each of the four categories. These results indicate that the coefficient of variation for between-field variations is several times larger for radar than for Landsat. Part of the variability in the radar data is attributed to system measurement precision. However, on the basis of radar measurements from individial "homgueneous" targets, the system variability is estimated to contribute less than 30 percent to the values given in Table 2 .

\subsection{Within-Field Variailce}

\section{A. Landsat}

In the Landsat image, variations in intensity among pixels of a given field are due to natural variations between different parts of the field, even though the field may be characterizes as nomogeneous on the basis of ground-truth information. The within-fieid variance for a field $i$ is given by

$$
\sigma_{w i \ell}^{2}=E_{j}\left(I_{i j}^{2}\right)-u_{i \ell}^{2}
$$

and the coefficient of variation for field $j$

$$
C_{w i \ell}=\sigma_{w i} / u_{i 2}
$$


ORIGINAL PAGE IS

OF POOR QUALITY

TABLE 2

Average Hithin-Field and Between-Field

Coefficients of Variation

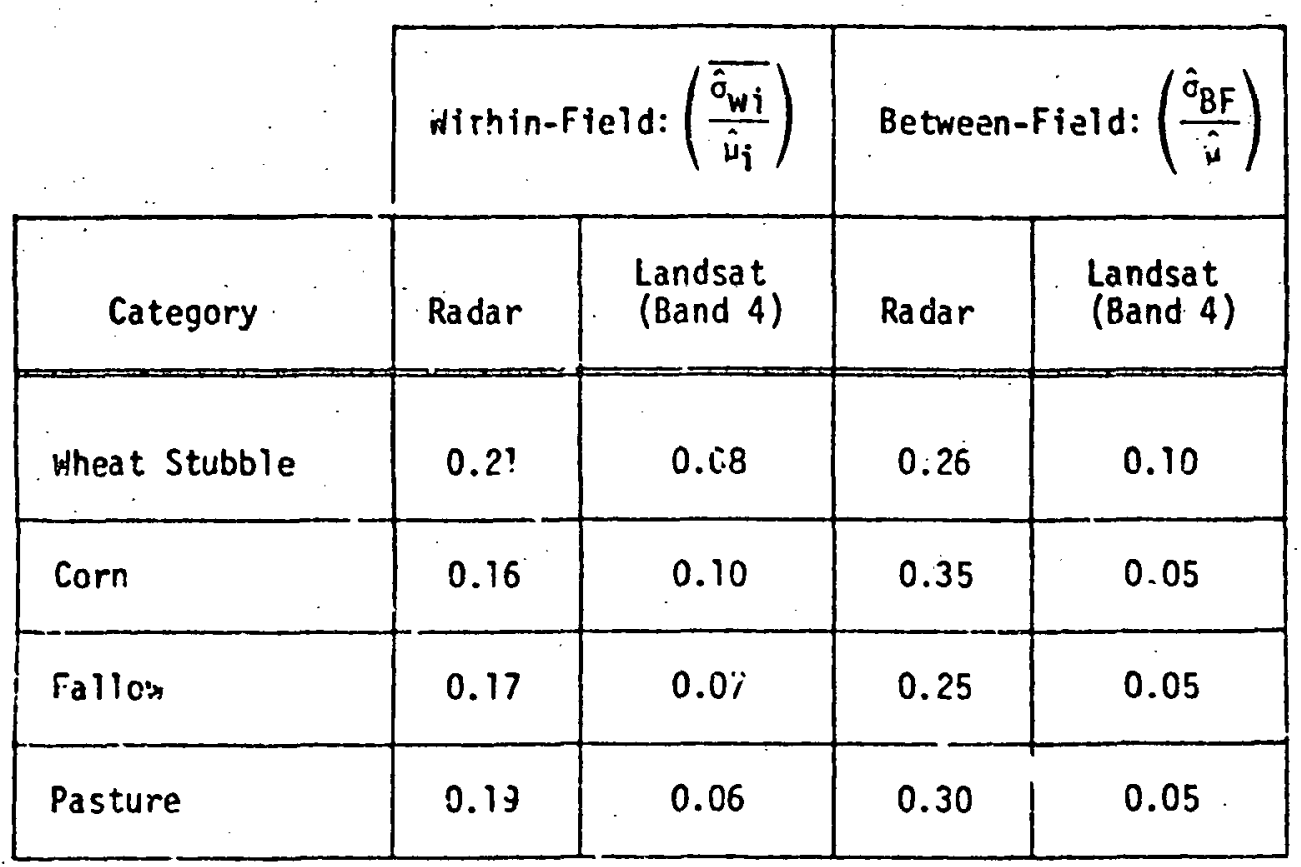




\section{ORIGINAL PAGE IS}

OF POOR QUALITY.

Estimated values of $C_{w l}$ are given in Table 2 for each of the four categories.

\section{B. Radar}

Computation of the within-field variability due to ndtural. variations within a given field is not as straightforward for the radar data as it is for the Landsat image. The reason is signal-fadirig due to the partially coherent nature of the radar measurements. Thus, the variabllity within a field is attributed to two statistical processes: natural variability and fading variability. The latter is governed by the radar measurement technique and therefore it is system-dependent. If the radar measurement ware made with an incoherent systrm or, equivalently, if the measurement is an average of a very large number of independent samples, then the only variability that would be observed among Jifferent cells of the same field would be due to natisral variability. The purpose of this section is to determine the within-field variance for such an incoherent system, and to develop a model for radar data tikat can be applied to any coherent radar system whereby the two sources of variance may be incorporated.

The scattering coefficient $s_{i j}$ of the $j^{\text {th }}$ cell of the $i^{\text {th }}$ field may be modeled by a multiplicative model $[13,14]$ of the form:

$$
S_{i j}=u_{i} \cdot \gamma_{i j} \cdot z_{N}
$$

where

$$
\begin{aligned}
\mu_{i}= & \text { true mean scattering coefficient of field } i_{s} \\
Y_{i j}= & \text { random variable accounting for the within-field natural } \\
& \text { spatial variability, } E_{i}\left(Y_{i j}\right)=\mu_{Y_{i}}=1 \text { for all } i, \\
Z_{N}= & \text { random variable accounting for signal fading, } Z_{N} \text { is } \\
& \text { described by a normalized } x^{2} \text { distribution with } 2 N \text { degrees } \\
& \text { of freedom, } E\left(Z_{N}\right)=1 .
\end{aligned}
$$

For $N>20$, the $x^{2}$ distribution approaches a truncated nomal distribution and $Z_{N}$ may be described by

$$
Z_{N}=1+\left(\frac{x}{\sqrt{N}}\right): \quad Z_{N} \geq 0
$$


where $X$ is a zero-mean random vartable described by a truncated nomal distribution such that $Z_{N} \geq 0$.

To compute the variance of $Y_{\text {if }}$ for a given field 1 , we first convert (II) into an additive model by expressing the terms in decibels (dB).

$$
10 \log S_{i j} \cdot 10 \log \mu_{i}+10 \log Y_{i j}+10 \log Z_{N}
$$

or

$$
S_{i j}=u_{i}+Y_{i j}+Z_{i}
$$

where $S_{i j} \$ 10 \log S_{i j}$, and similarly for the other terms. The random variables $Y_{i f}$ and $Z_{N}$. accounting respectively for the natural spatial variability and for tie fading variability, are governed by independent physical processes, and therefore they nay be considered statistically independent. With $u_{j}(d B)$ being a constant for fleld $i$, the variance of $S_{i j}(d B)$ is

$$
\sigma_{S_{i}}^{2}=a_{Y_{i}}^{2}+\sigma_{Z_{N}}^{2}
$$

The vartance " $s_{j}$ is computed from measured values of $S_{i j}^{\prime}$ for $j=1, N_{c r}$. ro compute the Jariance o $z$. we first need to determine the probability density function $f_{Z_{N}}\left(Z_{N}^{\prime}\right)$. "The random variable $Z_{N}$ is given by

$$
Z_{N}^{\prime}=10 \log \left(1+\frac{X}{\sqrt{N}}\right)
$$

$=10 \cdot \log (\sqrt{N}+x)-10 \log \pi$

$=T+10 \log \sqrt{N}$

where $T \stackrel{\wedge}{a} 10 \log (\sqrt{N}+x)$

As was stated earlier, $x$ is described by a truncated zero-mean normal distribution.

$$
f_{x}(x)=\frac{1}{\sqrt{2 \pi}} \exp \left(-\frac{x^{2}}{2}\right) \quad-\sqrt{N} \leq x \leq \infty
$$

with the lower limit being mandated by the fact that $Z_{N}$ cannot be negative becau:e it represents power. 


\section{ORIGINAL PAGE IS. \\ OF POOR QUALITY}

From (17) and (18) the probability density function of $T$ is given by:

$$
f_{T}(T)=J f_{X}(x)
$$

where $J$ is the Jacobtan,

$$
J=\frac{d X}{d T}=-10^{T / 20} \text { en } 10
$$

Hence,

$$
f_{T}(T)=\frac{\ln 10}{\sqrt{2 \pi}} 10^{T / 1 r} \exp \left\lfloor-\frac{\left(10^{T / 10}-\sqrt{N}\right)^{2}}{2}\right\rfloor,-\infty \leqslant T \leqslant \infty
$$

Finally, using (16), a change of variables leads to

$$
f_{Z_{N}^{\prime}}\left(Z_{N}^{\prime}\right)=\frac{\ln 10}{\sqrt{2 \pi}} 10^{Z_{N}^{\prime \prime}} \exp \left[-\frac{\left(10^{Z_{N}^{\prime \prime}}-\log \sqrt{N}\right)^{2}}{2}\right],-\infty \leq Z_{N}^{\prime} \leq \infty
$$

where

$$
z_{N}^{\prime \prime} \cong \frac{z_{N}^{\prime}}{10}-\log \sqrt{N}
$$

Plots of $f_{Z_{N}^{\prime}}\left(Z_{N}^{\prime}\right)$ are shown in Figure 1 for $N=16$ and $N=64$; the curves are skewed-nomal in shape.

Using (20), the variance $a_{Z N}^{2}$ was computed for several values of $N$ and is shown in Figure 2.

For the radar scatterometer data available to this study, $N=69$ [12] on the basis of the sensor and aircraft parameters and the usually assumed Rayleigh fading model. With $N$ known, $0_{Z N}^{2}$ was computed empirically using the density function given in $(20)$ and then used in (15) to determine ${ }^{\sigma} Y_{i}$. the within-field variance due to natural spatial variability $\left({ }^{\circ} S_{i}\right.$ was estimated from measured values of $S_{i j}$, as stated earifer). After repeating this process for all fields of each category, the averige values of $\left.{ }^{\circ} S\right\}$ and ${ }^{\circ}{ }_{Y_{1}}$ over 1 were computed and are given in Table 3.

For comparison to Landsat, the variance $o_{Y}^{2}$ is obtained from $o_{Y i}^{2}$. by assuming that $Y$ is nomally distributed. This assumption is based on the observation that the scattering coefficient of vegetation tarqets is approximately nomally distributed when expressed in dB [15]. Further, 33 out of 36 flelds passed the Kolmogorov-Sinirnov nomality test [17] 
ORIGINAL PAGE IS

OF POOR QUALITY

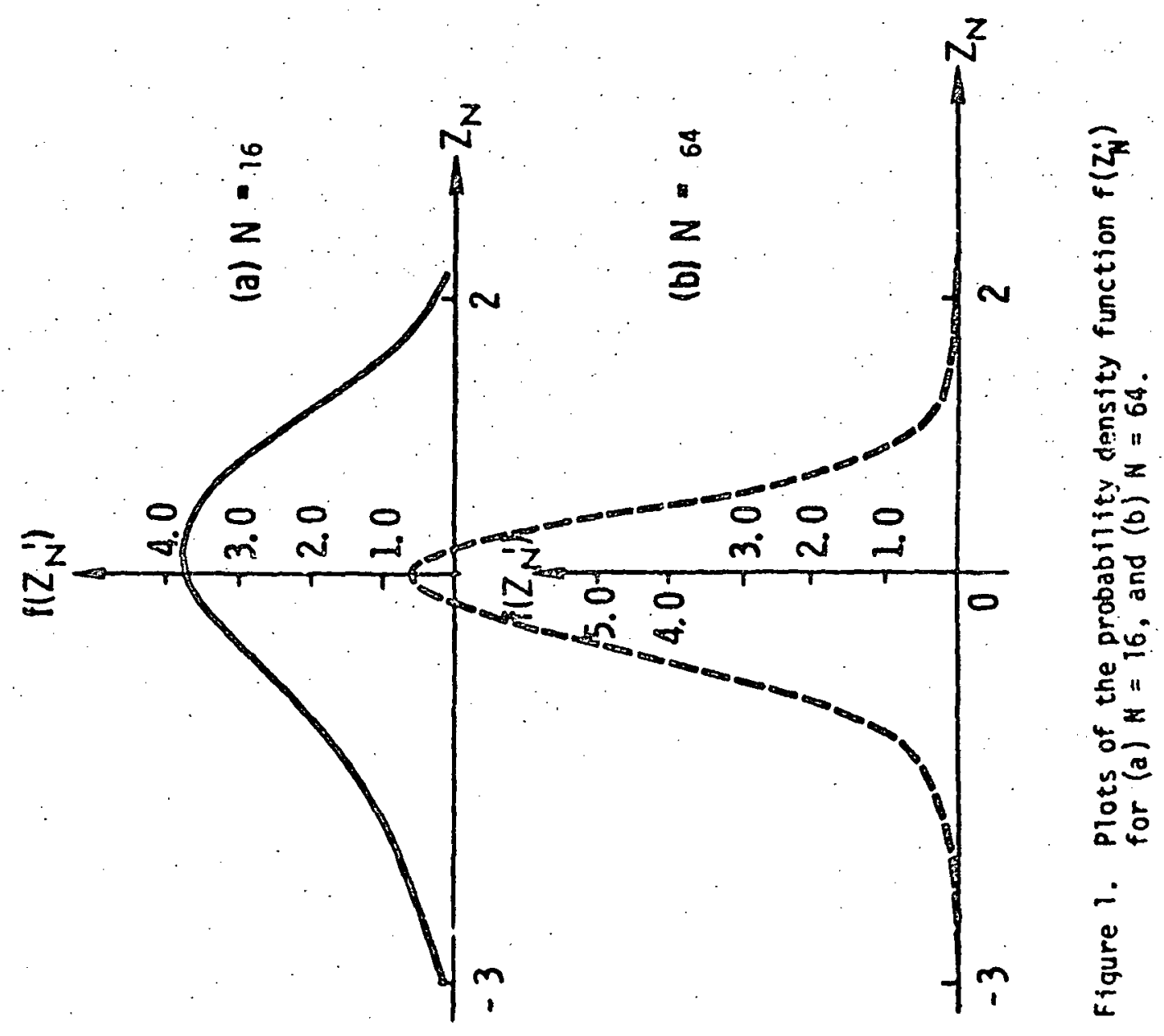




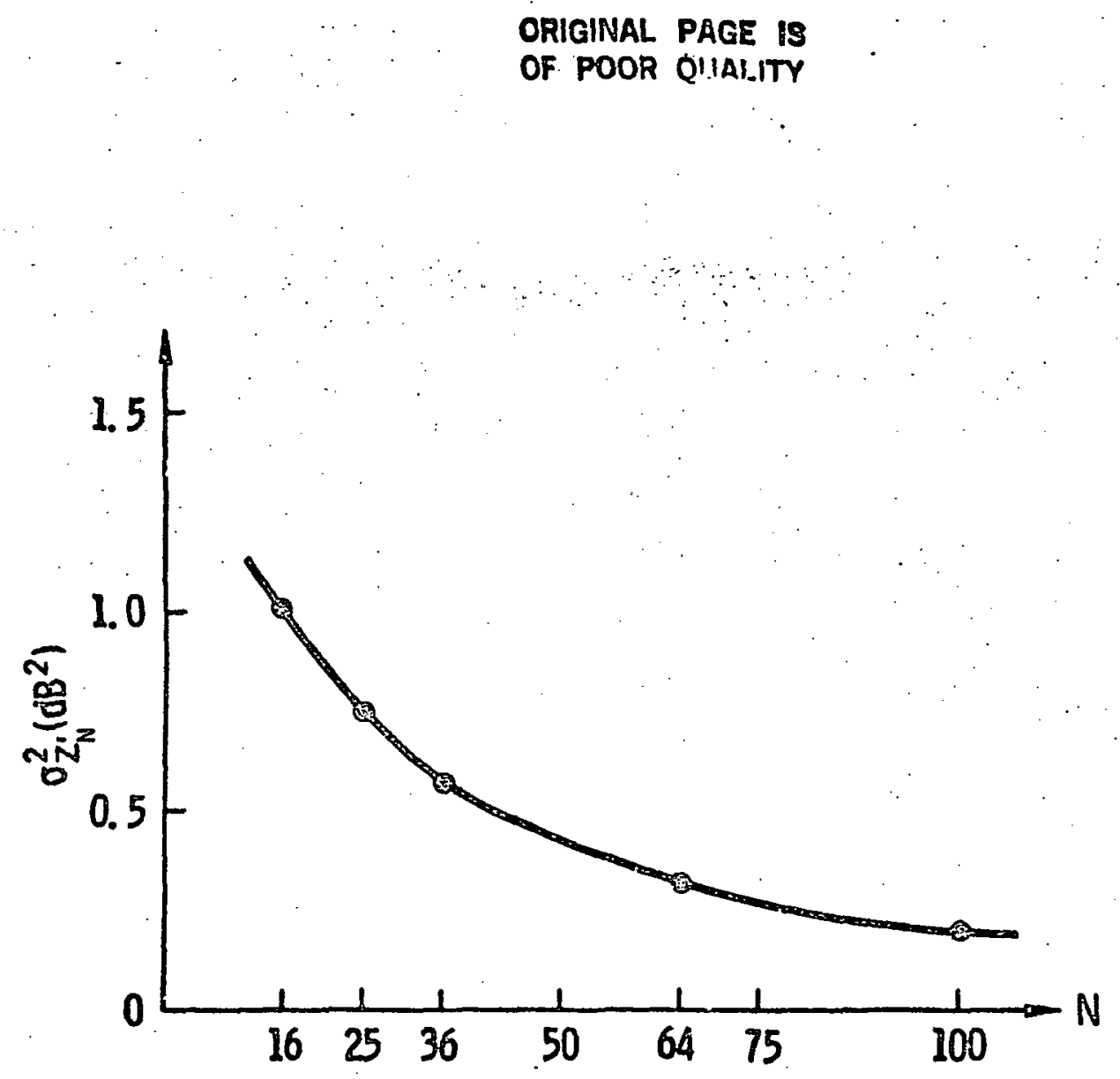

Figure 2. Plot of $\sigma_{Z_{N}^{\prime}}^{2}$ as a function of the number of the independent samples $N$. 
ORIGINAL PAGE IS

OF POOR QUALITY

TABLE 3

Relative Contributions of Fading (with $N=69$ ) and Spatial Variances to the Total Within-Field Variance of $S^{\prime}$ (Scattering Coefficient in $d B$ )

\begin{tabular}{|l|c|c|c|}
\hline & $\begin{array}{c}\text { Average Total } \\
\text { Within-Field } \\
\text { Variance, } \hat{\sigma}^{2}\end{array}$ & \multicolumn{2}{|c|}{ Relative Contributions } \\
\cline { 3 - 4 } Wheat Stubble & $1.10 \mathrm{~dB}^{2}$ & $0.28 \mathrm{~dB}^{2}$ & $0.82 \mathrm{~dB}^{2}$ \\
\hline Corn & $0.76 \mathrm{~dB}^{2}$ & $0.28 \mathrm{~dB}^{2}$ & $0.48 \mathrm{~dB}^{2}$ \\
\hline Fallow & $0.83 \mathrm{~dB}^{2}$ & $0.28 \mathrm{~dB}^{2}$ & $0.55 \mathrm{~dB}^{2}$ \\
\hline Pasture & $0.94 \mathrm{~dB}^{2}$ & $0.28 \mathrm{~dB}^{2}$ & $0.66 \mathrm{~dB}^{2}$ \\
\hline
\end{tabular}




\section{ORIGINAL PAGE IS}

OF POOR QUALITY

at the 0.05 significance-level when applied to $S_{i j}$ (scattering coefcient expressed $(n d B)$. From

$$
\begin{aligned}
Y_{i j} & =10 \log Y_{i j} \\
& =4.3 \ln Y_{i j}
\end{aligned}
$$

we define

$$
Y_{i j}^{\prime \prime}=\frac{Y_{i j}}{4.3}=\ln Y_{1 j}
$$

For a given field $i, Y_{i j}^{\prime}$ (and therefore $Y_{i j}^{\prime \prime}$ ) is assumed to be nomally distributed. Hence, the variance of $Y_{f}$ is given by [18]:

$$
\begin{aligned}
\sigma_{Y_{i}}^{2} & =\mu_{Y_{i}}\left[\exp \left(\sigma_{Y_{i}^{\prime \prime}}^{2}\right)-1\right] \\
& =\exp \left(\sigma_{Y_{i}^{\prime \prime}}^{2}\right)-1
\end{aligned}
$$

since ${ }_{Y_{i}}=$ ? for all 1 . Converting back to $Y_{i}^{\prime}$, we have

$$
\sigma_{Y_{i}}^{2}=\exp \left(\frac{\sigma_{Y i}^{2}}{18.5}\right)-1
$$

Using the values of $\sigma_{Y\}}^{2}$ computed earlier, $\sigma_{Y_{f}}^{2}$ was obtained for each value of $i$ using the above expression. The average value of $Y_{i}$ over $i$ is given in Table 2 for the four cover categories. The results given in Table 2 indicate that radar data exhibit much larger within-field variability compared to Landsat data.

For each category, the total variance $\sigma_{T}^{2}$ is computed from:

$$
\sigma_{T}^{2}=E_{i j}\left[\left(S_{i j}^{\prime}\right)^{2}\right]-\left(\mu^{\prime}\right)^{2}
$$

where the averaging is performed over all $S_{i j}$ values, with $j=1$, $N_{c r}$ and $i=1, N_{f}$, and $\mu^{\prime}=10 \log \mu_{r}$. Thus, of inciudes all sources of variance including fading, within-field and between-field. Table 4 compares the values of $\sigma_{T}$ computed from the 1978 data with the results 
ORIGINAL PAGE IS

OF POOR QUALITY

TABLE 4

Comparison of Total Standard Deviation $\hat{q}$. Incorporating Fading, Within-Field and Between-Field Variations

\begin{tabular}{|c|c|c|c|c|c|}
\hline & & Hheat & Com & Bare Soll & Milo \\
\hline$\hat{a}_{T}, \mathrm{~dB}$ & $6 / 28 / 70$ & 1.05 & 1.3 & 1.35 & 1.65 \\
\hline
\end{tabular}

\begin{tabular}{|c|c|c|c|c|c|}
\hline & & $\begin{array}{c}\text { Hheat } \\
\text { Stubble }\end{array}$ & Corn & Bare Soil & Pasture \\
\hline$\hat{o}_{\mathrm{T}} \mathrm{d} \mathrm{d} B$ & $7 / 18 / 78$ & 1.37 & 1.6 & 1.39 & 1.59 \\
\hline
\end{tabular}

1970: $13.3 \mathrm{GHz}$ VV, 600 measurements [16]

1978: $13.3 \mathrm{GHz}$ VV, 360 measurements [this study] 
from a similar data set obtained in 1970 [16] with the same radar scatterometer system. It is noted that.the two sets of values are comparable in magnitude and range, although not all the categories are identical for the two data sets. Histograms of $S_{i j}$ are shown in Figures 3-5 for corn, wheat stubble, and bare soil. The histograms appear approximately normal in shape.

\subsection{CLASSIFICATION RESULTS}

The available radar data were obtained from flights on $7 / 18 / 78$ and $7 / 20 / 78$. Usualiy, one would not expect any significant additional information to be derived from the second flight, since it was in such close time-proximity to the first one except, in this case, a rainfall of $1.9 \mathrm{~cm}$ occurred on $7 / 19 / 78$, the day between the two flights. Hence, this occasion provides an opportunity to evaluate the effect of rain on crop-identification accuracy.

The cloud-free Landsat pass in closest proximity to the radar flights was on $7 / 26 / 78$, approximately a week after the radar acquisition dates. In the discussion below, the classification results obtained on. the basis of the Landsat data above will be presented first, followed by presentations of the radar results and the results obtained using both types of sensors in combination.

\subsection{Landsat Alone}

A total of 1,080 Landsat pixels were available for classification. Using a linear Bayes classifier, the results shown in Figuine 6 were obtained. On a single-band basis, Band $a$ gave the best results with $67 \%$ of the pixels being correctly recognized. The addition of the other bands improved the classification accuracy to $75 \%$. Time crop confusion table for Band 4 alone is qiven in the top part Table 5 .

\subsection{Radar Alone}

The distributions of values for the field-mean scattering coefficient are shown in Figure 7 for each. cover cateqory. Indiacated on each vertical bar are the maximum, mean, and minimum values of $\mu_{i r}$. The :-....... : - ....... 


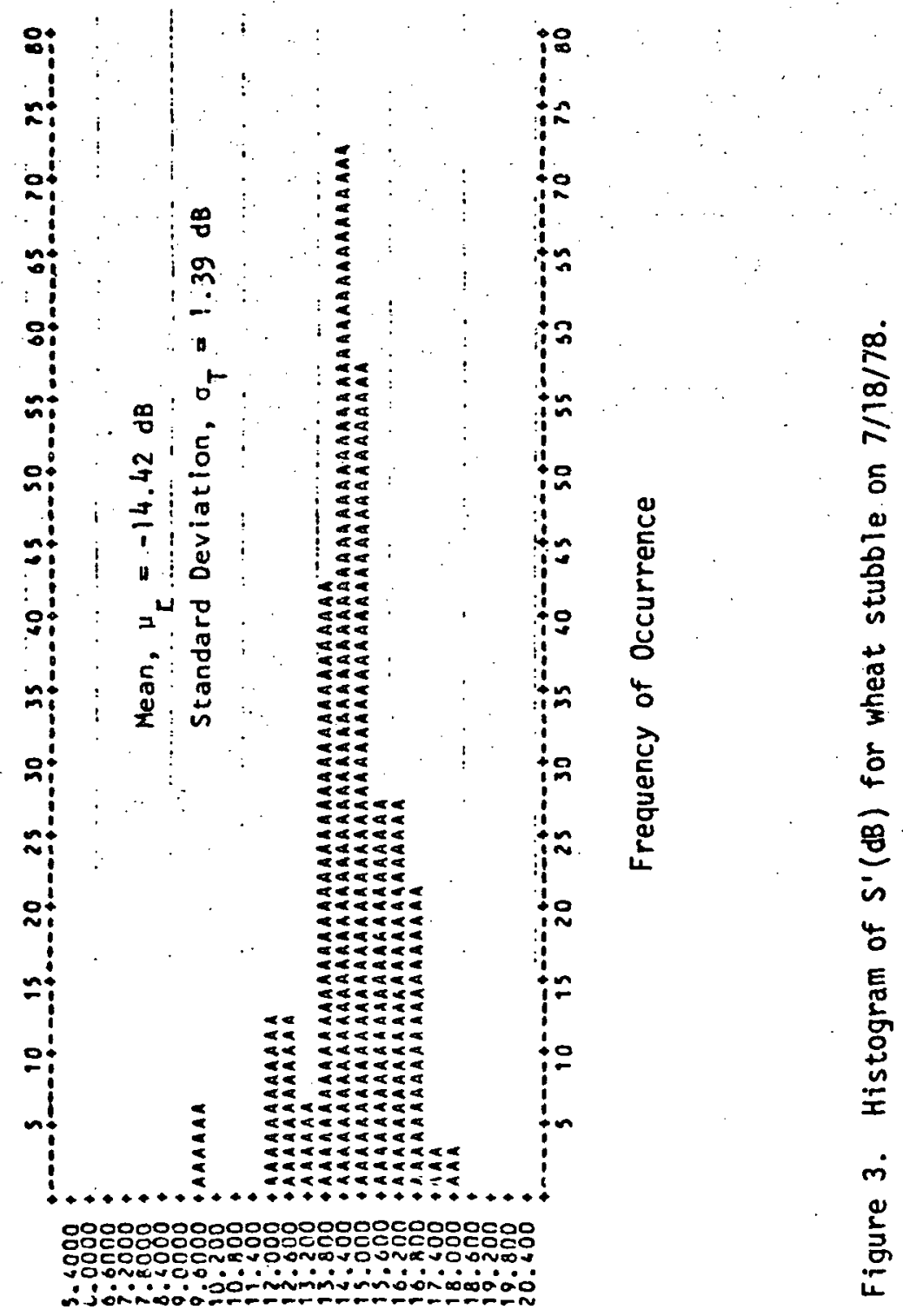

$|1| 1|1| 1|1||1| 1|1| 1|1| 1|1|$

(gP) , S 


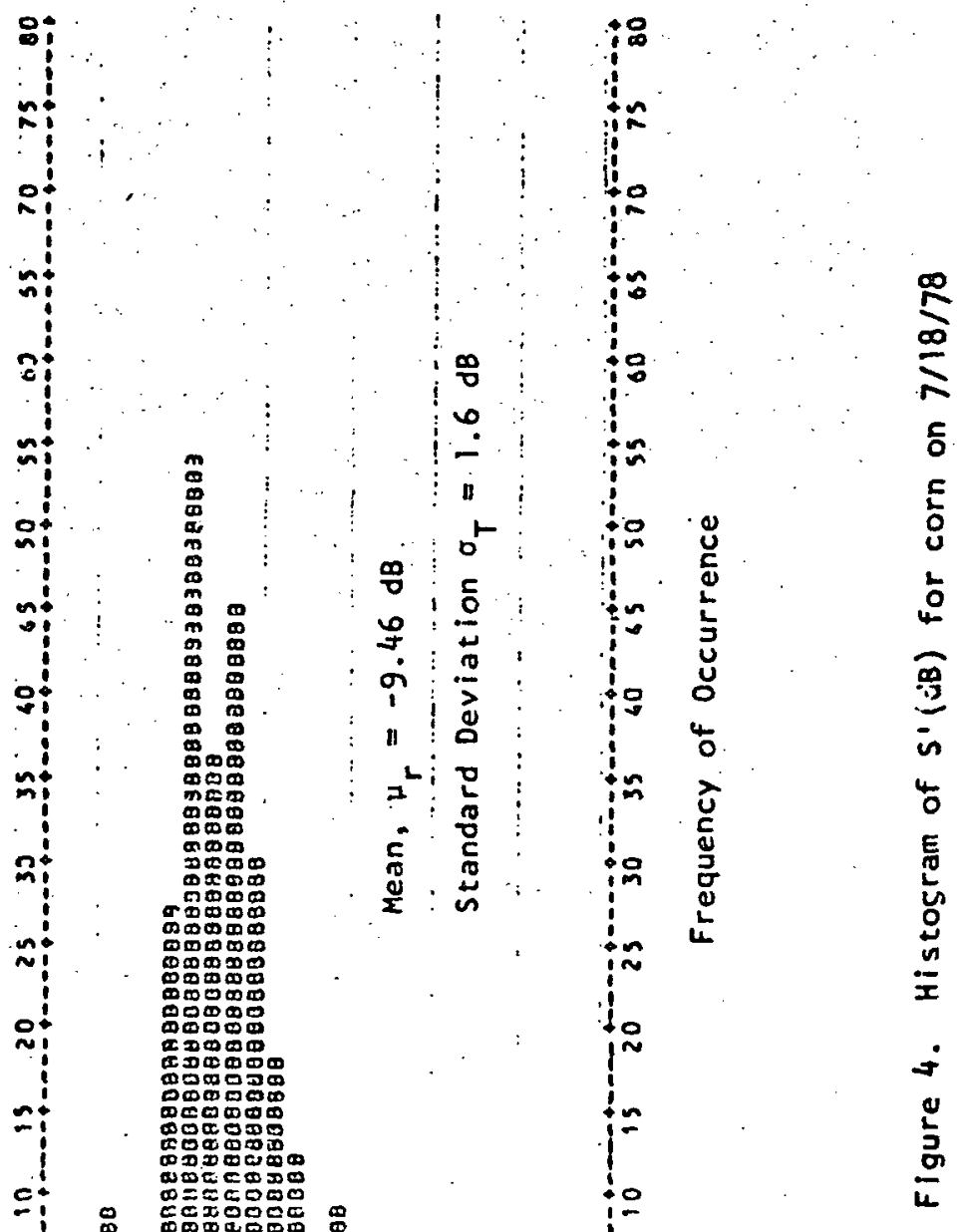


" denotes estimated values

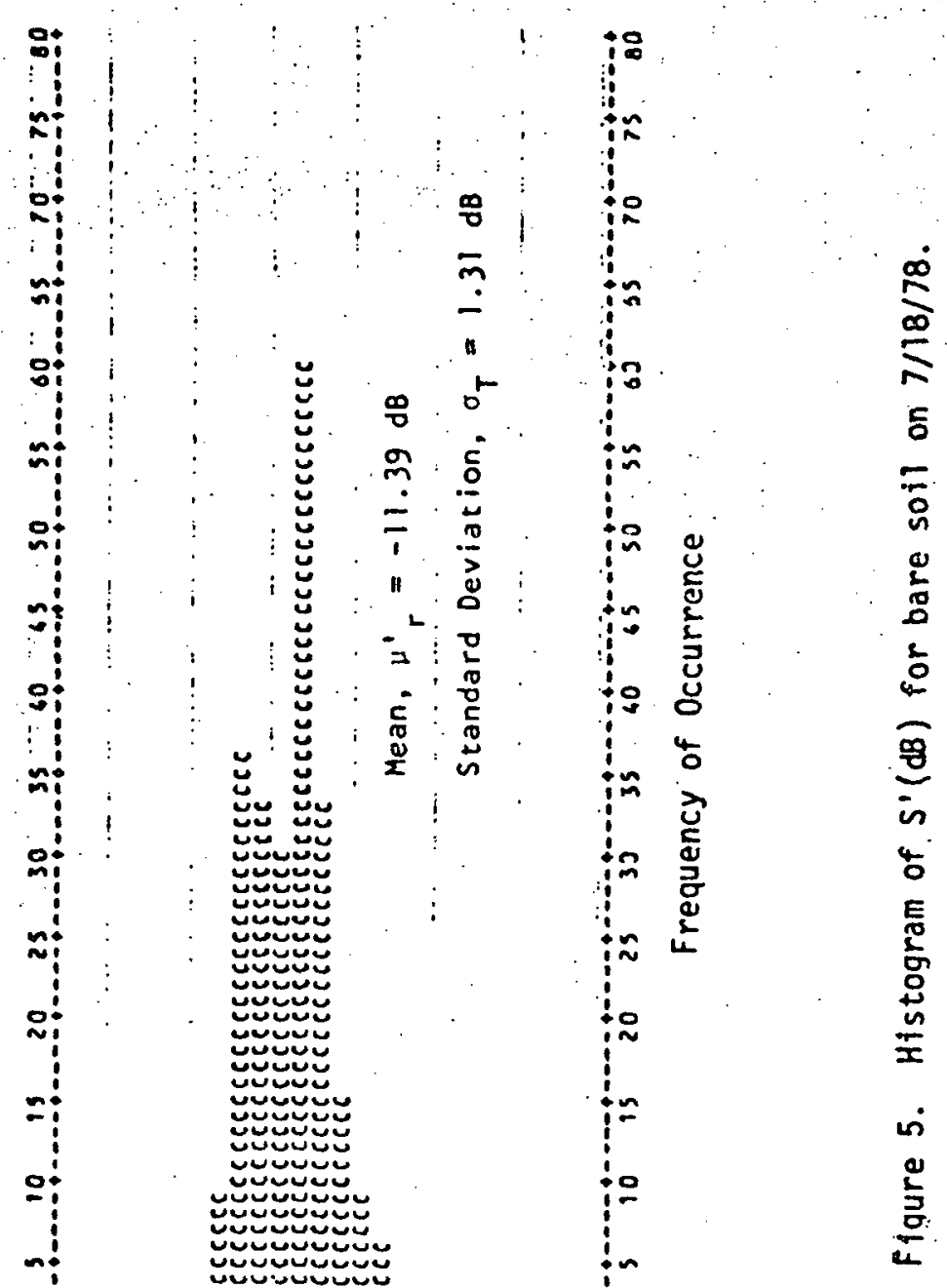


coefficient of variation is:

$$
C_{w \ell}=E_{j}\left(C_{w i \ell}\right)
$$

ORIGINAL PAGE IS

OF POOR QUALITY

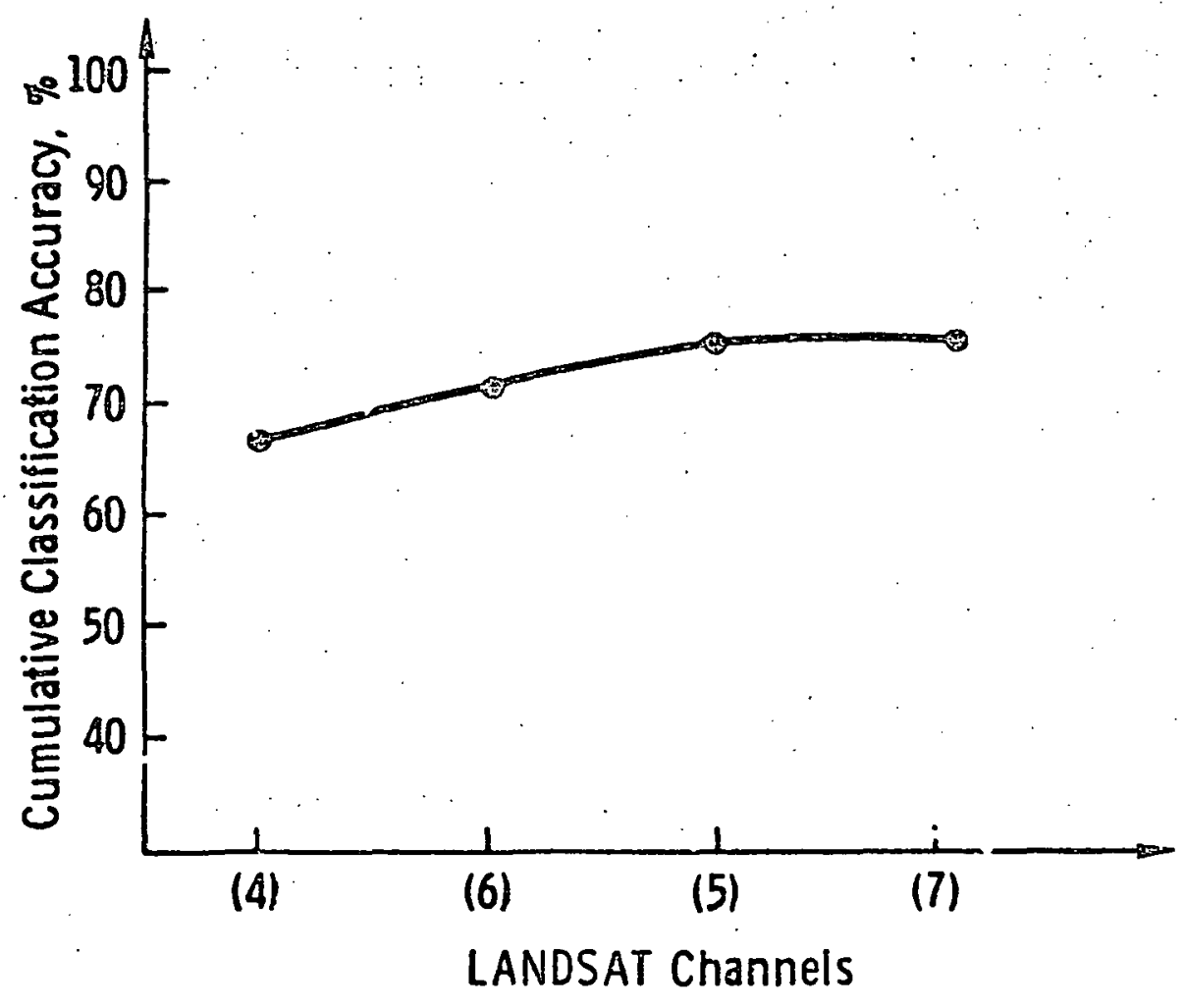

Daía Form: LANDSAT Bands 4, 5, 6 and 7

Pixels Used: 1080

Categories: Wheat Stubble, Corn, Fallow and Pasture Date: July 26, 1978 


\section{ORIGINALI PAGE IS \\ OF POOR Q'JALITY}

T.ABLF. 5

Crop Confusion Tables for (a) Landsat Alone,

(b) Radar Alone, and (c) Both Combinea

(a) Landsat Alone

\begin{tabular}{|l|c|c|c|c|}
\hline $\begin{array}{l}\text { Classified } \\
\text { Actual }\end{array}$ & $\begin{array}{c}\text { Wheat } \\
\text { Stubble }\end{array}$ & Corn & Fallow & Pasture \\
\hline $\begin{array}{l}\text { Wheat } \\
\text { Stubble }\end{array}$ & 29.2 & 1.0 & 30.3 & 39.4 \\
\hline iorn & 0.6 & 93.7 & 0.0 & 5.8 \\
\hline Fallow & 9.0 & 0.7 & 88.3 & 2.0 \\
\hline Pasture & 36.7 & 0.0 & 13.3 & 50.0 \\
\hline
\end{tabular}

Feature Used: Landsat Imagery Band 4 on $7 / 26 / 78$

Tota: Classification Accuracy: $67.0 \%$

(b) Radar Alone

\begin{tabular}{|l|c|c|c|c|}
\hline $\begin{array}{l}\text {.1assified } \\
\text { Actual }\end{array}$ & $\begin{array}{c}\text { Wheat } \\
\text { Stubble }\end{array}$ & Corn & Fall Jw & Pasture \\
\hline $\begin{array}{l}\text { Wheat } \\
\text { Stubble }\end{array}$ & 70.8 & 1.6 & 8.3 & 19.1 \\
\hline Corn & 3.6 & 70.0 & 26.3 & 0.0 \\
\hline Fallow & 13.0 & 19.0 & 68.0 & 0.0 \\
\hline Pasture & 13.3 & 0.0 & 0.0 & 86.6 \\
\hline
\end{tabular}

Feature Used: Radar Measured fixels $(d B)$ on $7 / 18 / 78$

Total Classification Accuracy: $71.1 \%$ 
TABLE 5 (contd.)

(c) Landsat and Radar

\begin{tabular}{|l|c|c|c|c|}
\hline $\begin{array}{l}\text { Classified } \\
\text { Actual. }\end{array}$ & $\begin{array}{c}\text { Wheat } \\
\text { Stubble }\end{array}$ & Corn & Fallow & Pasture \\
\hline $\begin{array}{l}\text { Wheat } \\
\text { Stubble }\end{array}$ & 71.3 & 1.6 & 7.7 & 19.1 \\
\hline Corn & 2.1 & 95.7 & 2.1 & 0.0 \\
\hline Fallow & 7.0 & 1.0 & 92.0 & 0.0 \\
\hline Pasture & 13.3 & 0.0 & 0.0 & 86.6 \\
\hline
\end{tabular}

Feature Used: Landsat Band 4 on $7 / 26 / 78$ and Radar Measured Pixels $(d B)$ on $7 / 18 / 78$

Total Classification Accuracy: $85.8 \%$ 


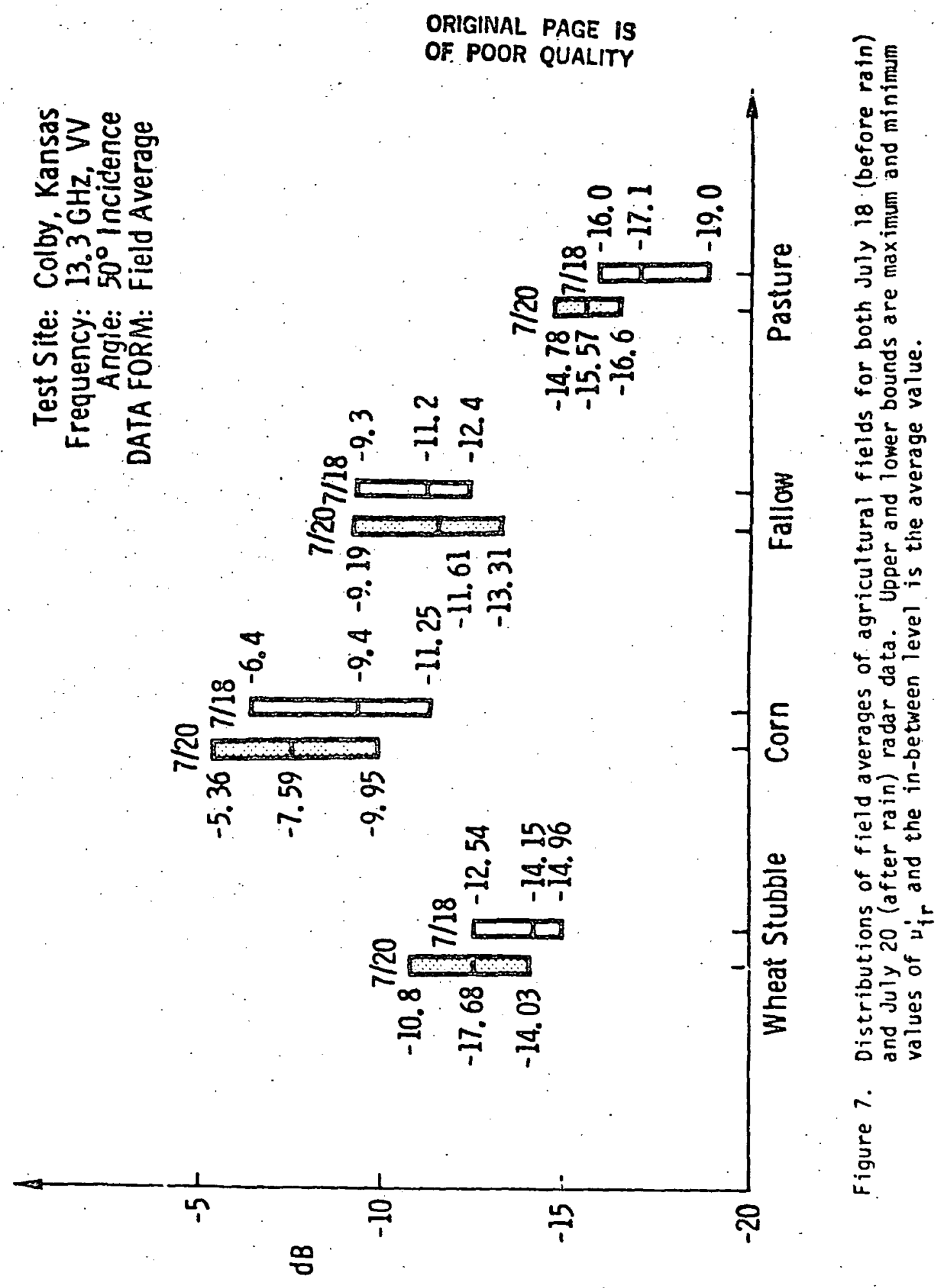


day varied the range of values of $\mu_{i r}$ for all categories except bare soll (fallow). For the entire data set as a whole, its mean value is $1.0 \mathrm{~dB}$ higher for the $7 / 20 / 78$ flight than for the $7 / 18 / 78$ flight. On a relative basis, the main effect of the rain is the greater overlap of the range of values of wheat stubble and fallow, which is likely to result in increased confusion between these two categories:

Single-date and multi-date radar classification results are shum in Figure 8, and the crop confusion tables are given in Table 6 for each of the two dates. The poorer results for the $7 / 20 / 78$ flight are due to increased confusion between wheat stubble and fallow, as expected.

Figure 9 compares the correct classification rates obtained on a pixel-by-pixel basis with those obtained on a field-by-field basis and, where for the former the radar classification was performed on $S_{i j}$. for the latter it was performed on $S_{j}^{\prime}$, the average scattering coefficient of field $i$ $\left\langle S_{i}=10 \log S_{i}=10 \log \sum_{j=1}^{N_{c r}} S_{i j}\right)$. Substantial improvement in classification accuracy is observed for the radar if field averages rather than pixel values are used in the classiffcation, due to larger within-field variance in radar data. The improvement is much smaller for Landsat.

\subsection{Landsat-RaCar Combined}

Following a procedure in which the radar resolution cells were stretched and skewed to match the Landsat pixels for each field, a matched set of Landsat-radar values were generated. Figures 10a and 10b. show the cumulative classification accuracy obtained using the landsat image of $7 / 26 / 78$, combined with the radar data of $7 / 18 / 78$ and $7 / 20 / 78$. resoectively. In both cases the Landsat Band 4 was chosen as the best first feature (highest F-ratio) followed by the radar. Combination of the $7 / 18 / 78$ radar data and the Landsat data yields a performance of $85 \%$, in comparison to $75 \%$ for Landsat alone. The improvement is smaller when Landsat data is combined with the $7 / 20 / 78$ radar data. When all four Landsat bands and both radar dates are used, the maximum correct classification accuracy obtained is $89.4 \%$. The crop confusion tables for Landsat alone, radar $(7 / 18 / 78)$ alone, and the combination of the two, are given in Table 5.

Cumulative classification results on a field-by-field basis, and the associated confusion table, are given in Fiqure 11. 


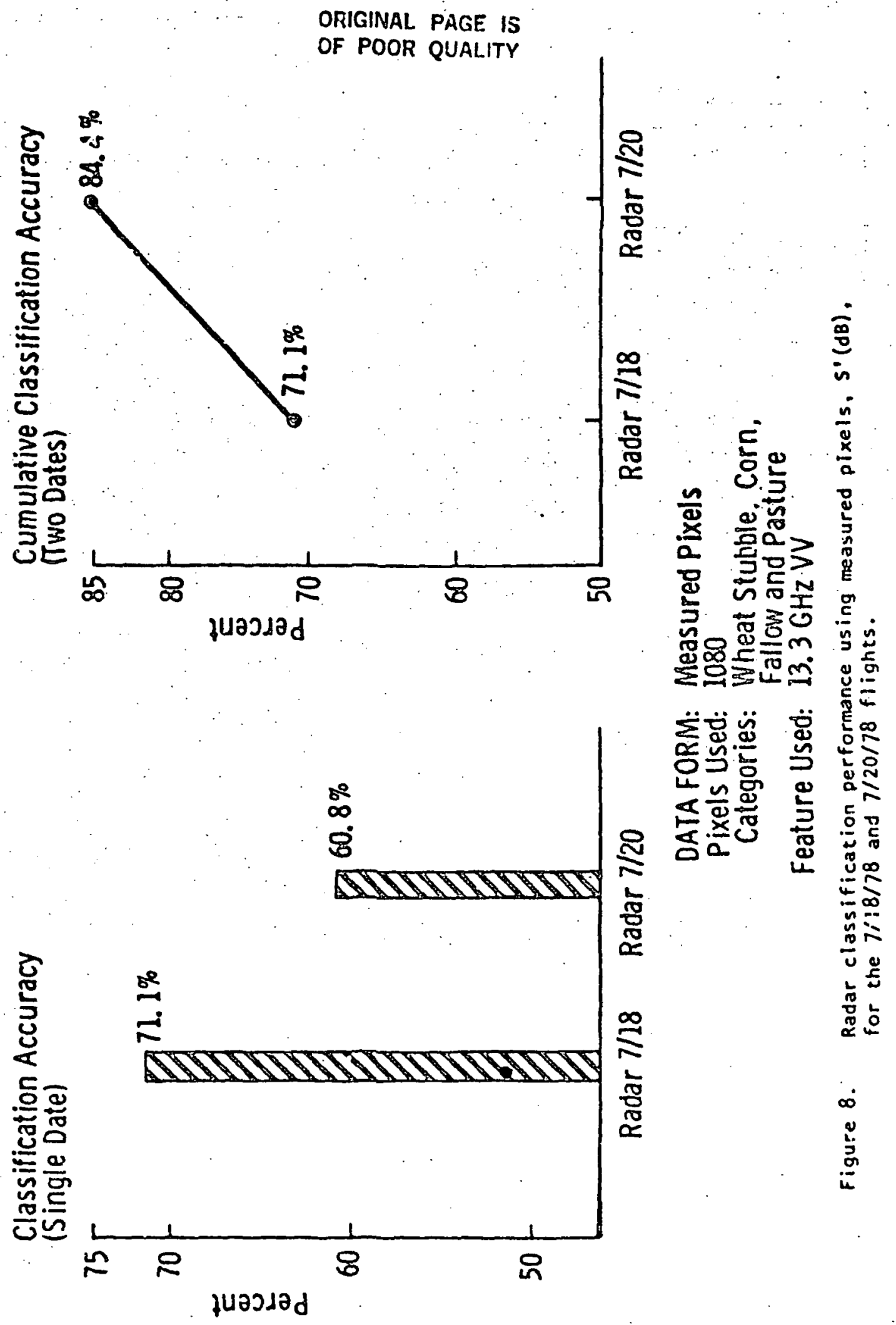


TABLE 6

Crop Confusion Tables for Radar Flights

of $7 / 18 / 78$ and $7 / 20 / 78$

(Before and After Ra in)

7/18/78 Flight:

(Before Rain)

\begin{tabular}{|l|r|r|r|r|}
\hline \multirow{2}{*}{$7 / 18 / 78$} & \multicolumn{4}{|c|}{ \% Classified } \\
\cline { 2 - 5 } & $\begin{array}{c}\text { Hheat } \\
\text { Stubble }\end{array}$ & Corn & Fallow & Pasture \\
\hline $\begin{array}{l}\text { Wheat } \\
\text { Stubble }\end{array}$ & 70.8 & 1.6 & 8.3 & 19.1 \\
\hline Corn & 3.6 & 70.0 & 26.3 & 0.0 \\
\hline Fallow & 13.0 & 19.0 & 68.0 & 0.0 \\
\hline Pasture & 13.3 & 0.0 & 0.0 & 86.6 \\
\hline
\end{tabular}

Total Classification Accuracy $=71.1 \%$

7/20/78 Flight:

(After Rain)

\begin{tabular}{|l|r|r|r|r|}
\hline \multirow{2}{*}{$7 / 20 / 78$} & \multicolumn{4}{|c|}{ \% Classified } \\
\cline { 2 - 5 } & $\begin{array}{c}\text { Wheat } \\
\text { Stubble }\end{array}$ & Corn & Fallow & Pasture \\
\hline $\begin{array}{l}\text { Wheat } \\
\text { Stubble }\end{array}$ & 39.1 & 0.0 & 34.1 & 26.6 \\
\hline Corn & 0.0 & 91.8 & 8.1 & 0.0 \\
\hline Fallow & 33.0 & 16.0 & 42.0 & 9.0 \\
\hline Pasture & 3.3 & 0.0 & 0.0 & 96.6 \\
\hline
\end{tabular}

Total Classification Accuracy $=60.8 \%$

Data From: Measured Pixels $S_{i j}^{\prime}(d B)$ 


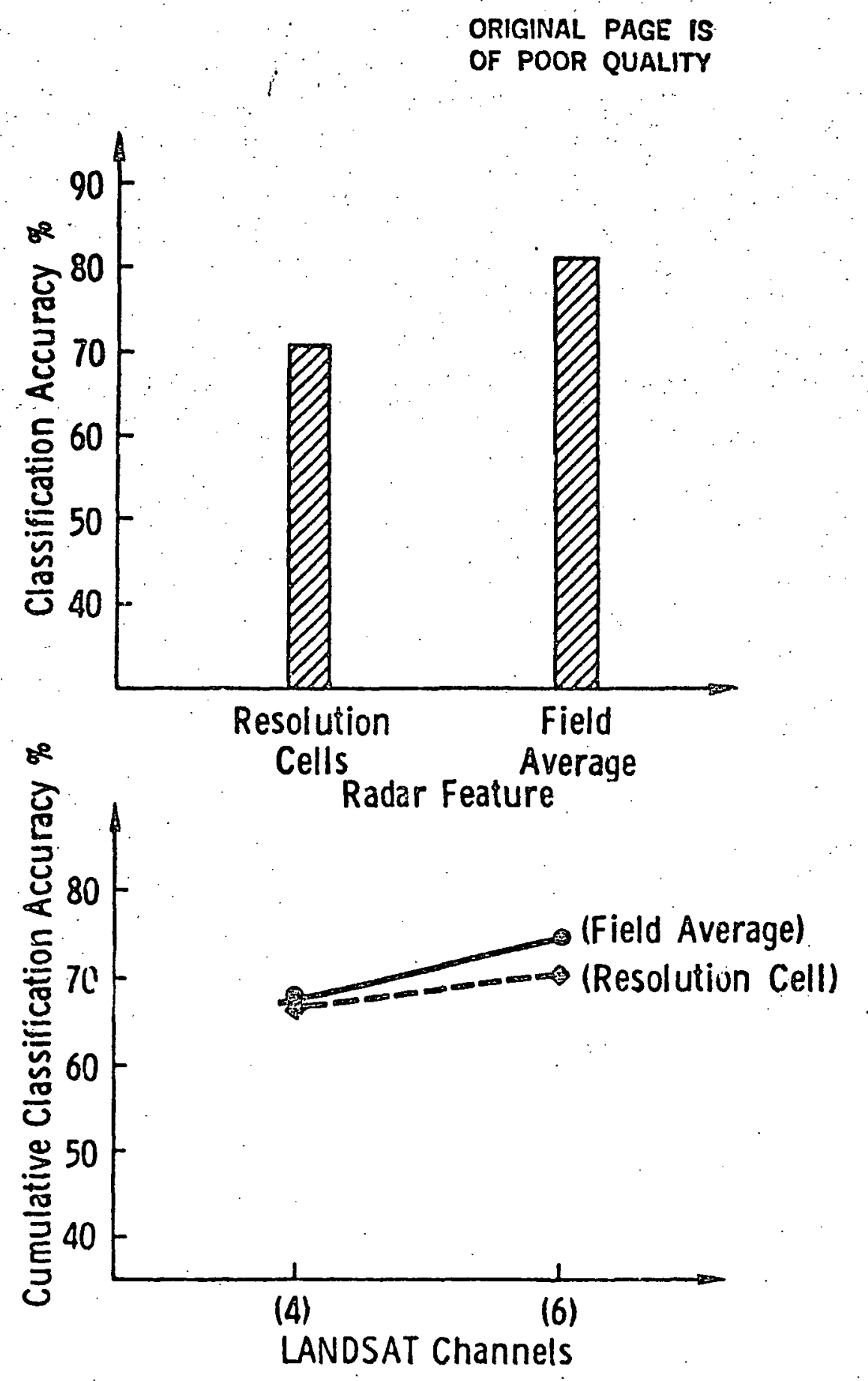

Figure 9. Comparison of classification accuracies obtained for classification applied on a pixel (cell)

bacis and on a fioldavorano hacie 
ORIGINAL PAGE IS

OF POOR QUALITY.

(a) Cumulative Classification Accuracy
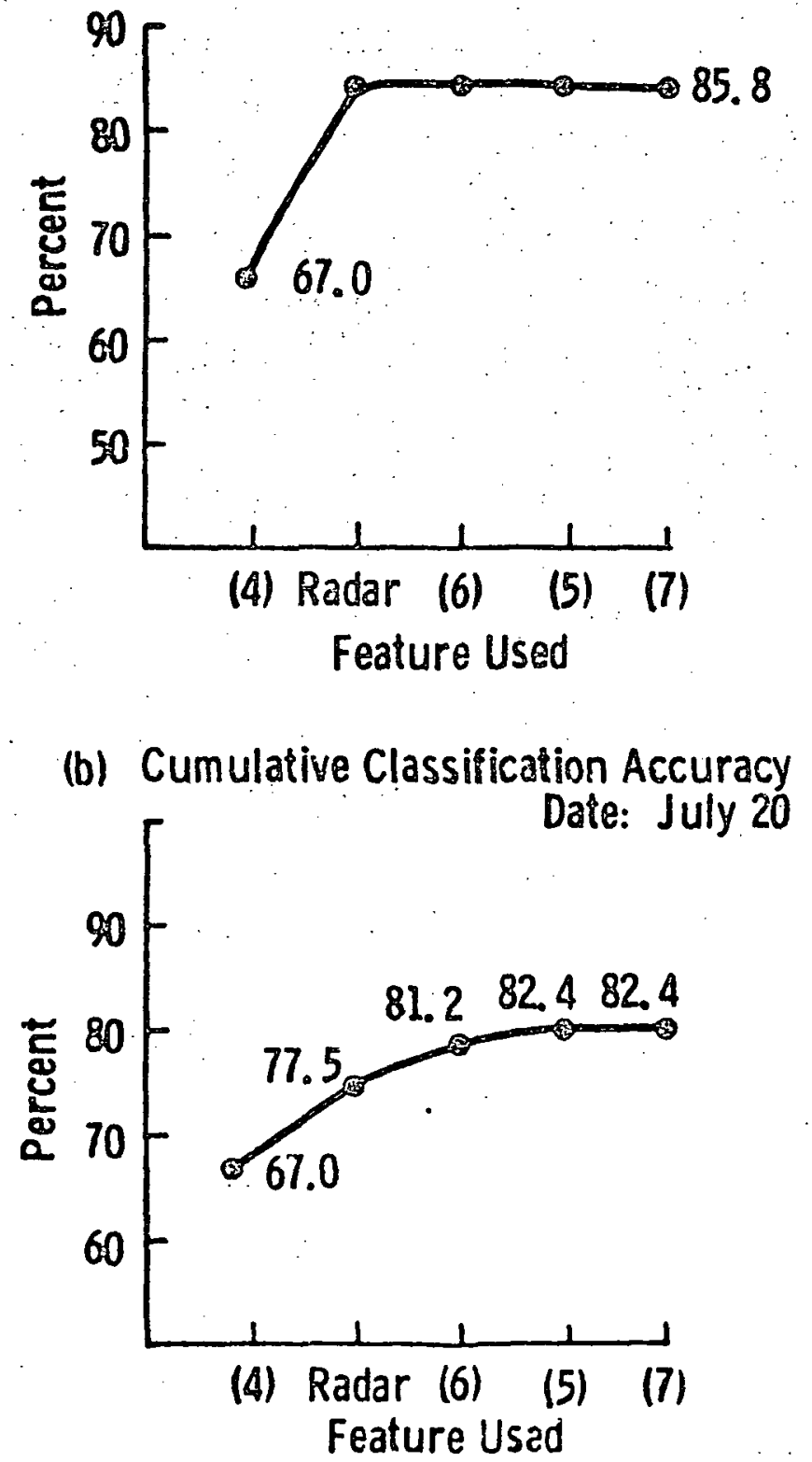

RADAR DATA FORM: Measured Pixels on $7 / 18 / 78$ and $7 / 20 / 78$. $S^{\prime}(d B)$ LANDSAT DATA: Bands 4, 5, $6 \& 7$ on 7/26/78 


\section{ORIGINAL PAGE IS \\ OF POOR QUALITY \\ Combined Radar/Landsat Classification}

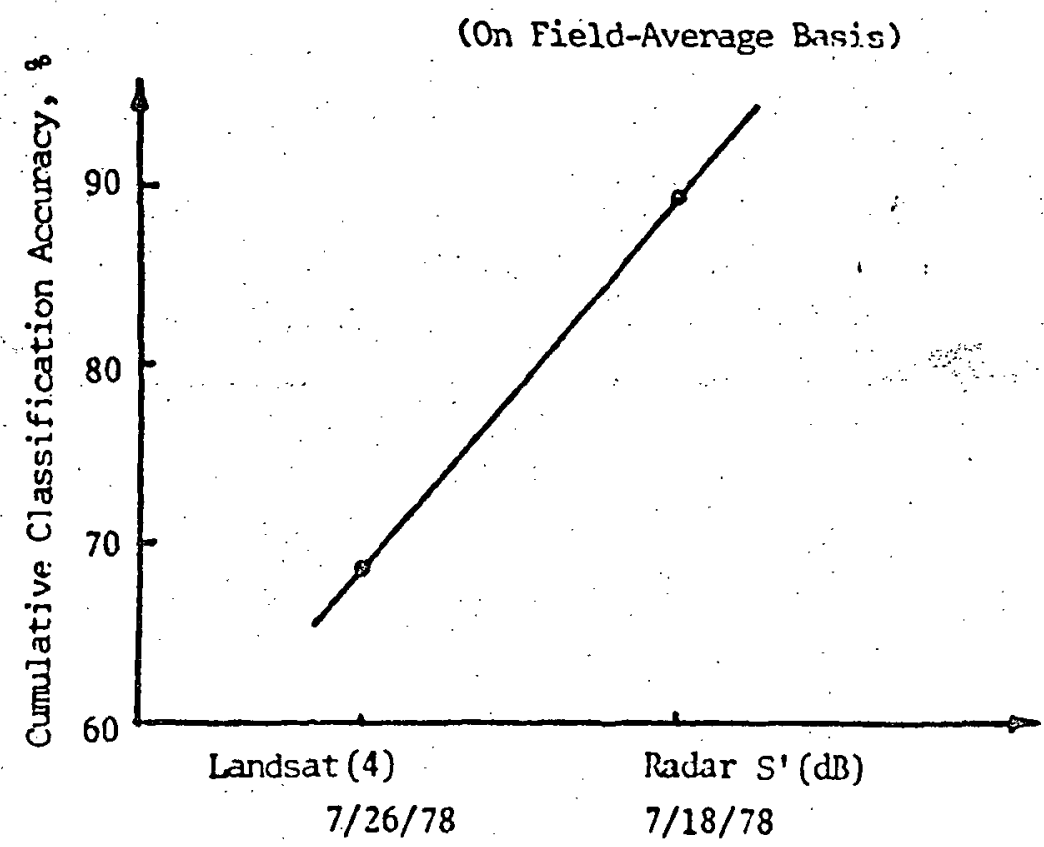

Crop Confusion Table

\begin{tabular}{|l|c|c|c|c|}
\hline $\begin{array}{c}\text { Classified } \\
\text { Actual }\end{array}$ & $\begin{array}{c}\text { Wheat } \\
\text { Stubble }\end{array}$ & Corn & Fallow & Pasture \\
\hline Wheat Stubble & 9 & 0 & 2 & 1 \\
\hline Corn & 0 & 11 & 0 & 0 \\
\hline Fallow & 0 & 0 & 10 & 0 \\
\hline Pasture & 0 & 0 & 0 & 3 \\
\hline
\end{tabular}




\subsection{Comparison of Classifiers}

Throughout the preceding sections, the classification tests were performed using the linear Bayes classifier. For comparison purposes, tests were performed using the four different classifiers indicated in Figure 12. The Euclidean-distance classifier provides the poorest performance, while the quadratic Bayes classifier gives the hiahest classification accuracy. The minimum-square-error (MSE) and linear Bayes classifiers are comparable to each other in performance and are slightly inferior to the quadratic Bayes classifier.

\subsection{CONCLUSIONS}

The major contributions and conclusions of this study are:

(a) A statistical model for radar backscatter was developed that accounts for the winthin-field natural variability and for signalfading, simultaneously. The model was applied to derive estimates of the within-field coefficient of variation and the results were compared with the same quantity derived from Landsat image data.

(b) Estimates for the Landsat and radar between-field coefficients of variation were copmuted and compared. The results show that the radar data exhibit larger within-field and between-field variations.

(c) Adding radar to Landsat improves the correct classification accuracy by about 10 percentage-points when classification is performed on a pixel basis and by about 15 percentage-points on a field basis. of course, in the absence of Landsat coverage due to clouds, the radar becomes the prime sensor for monitoring crops.

(d) The results obtained in this study pertain to the cover-types, geographic location and time-period specifled. Further research is needed to evaluate the statistical nature of the radar backscatter and the combined performance of optical and radar sensors using multidate data and other geographic regions. 


\section{ORIGINAL PAGE Is \\ OF POOR QUALITY}

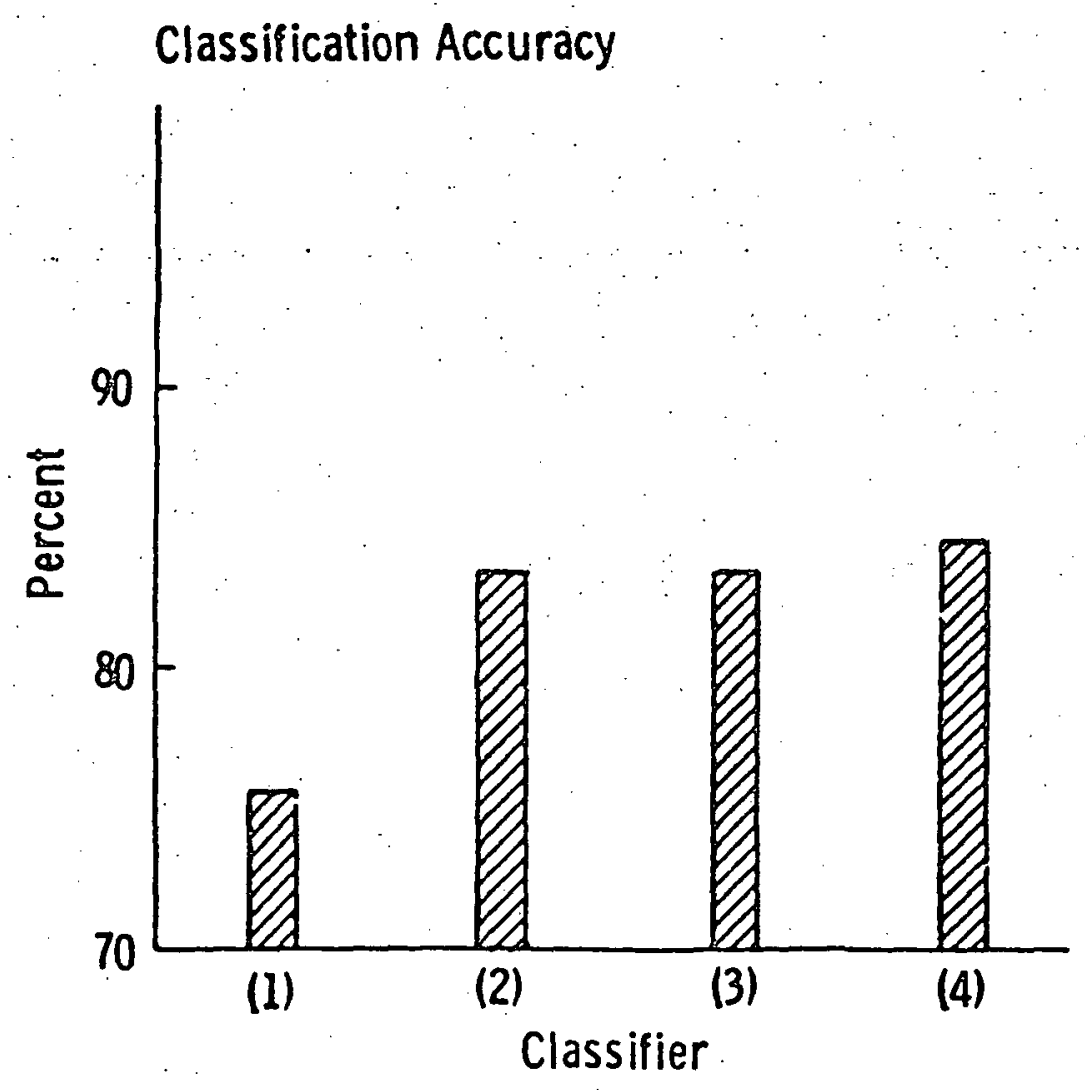

(1) Euclidean-Distance

(2) MSE

(3) Linear Bayes

(4) Quadratic Bayes

Feature: LANDSAT (4) + Radar 13.3. GHz, VV Pixels used: 1080 


\section{ACKNONLEDGHENT}

This research was supported by the National Aeronautics and Space Administration, Lyndon B. Johnson Space Center, Houston, Texas, Contract NAS 9-15421. 
$\cdot 9$

\section{REFERENCES}

[1] Ulaby, F. T., "Radar Response to Vegetation," IEEE Trans. on Antennas and Prop., AP-23, No. 2, January 1975.

[2] Vlaby, F. T., G. A. Bradley and M. C. Dobson, "Microwave Backscatter Dependence on Surface Roughness, Soil Moisture and Soil Texture, Part II: Vegetation-Covered Soil," IEEE Trans. on Geoscience Electronics, GE-17, No. 2, pp. 33-40, ApriT 1979.

[3] Ulaby, F. T., T. F. Bush and P. P. Batlivala, "Radar Response to Vegetation, II: 8-18 GHz Band," IEEE Trans. on

Antennas and Prop., AP-23, No. 5, pp. 608-678, September 1975.

[4] Bush, T. F. and F. T. Ulaby, "An Evaluation of Radar as a Crop Classifier," Remote Sensing of Environment, 7, pp. 15-36, 1978.

[5] Simonett, D. S., J. E. Eagleman, A. B. Erhard, D. C. Rhodes and D. E. Schviarz, "The Potential of Radar as a Remote Sensor in Agriculture, I: A Study with K-Dand Imagery in Western Kansas," CRES Report 61-21, University of Kansas, Lawrence, Kansas, 1967.

[6] Haralick, R. M., F. R. Caspall and D. S. Simonett, "Using Radar Imagery for Crop Discrimination: A Statistical and Conditional Probability Study," Remote Sensing of Environment, 1, pp. 131-142, 1972 .

[7] Schwarz, D. E. and F. R. Caspall, "The Use of Radar in the Discrimination of Ayricultural Land Use," in Proc. 5th Symp. Rem. Sens. of Env... 1, pp. 233-247, 1968.

[8] Ulaby, F. T.. P. P. Batlivala and J. E. Bare, "Crop Identification with L-Band Radar," Photogrammetric Engineering and Remote Sensing, 46, No. $i$, pp. 107-105, January 198?.

[9] Brisco, B. and R. Protz, "Corn Field Identification Accuracy Using Airborne Radar Imagery," Canadian J. Rem. Sens., 6, No. 1 , July 1980, pp. 15-25.

[10] Li, R. Y., F. T. Ulaby and J. R. Eyton, "Crop Classification with a Landsat-Radar Sensor Combination," Proc. Symp. on Machine Processing of Remotely Sensed Data, Purdue University, West Lafayette, Indiana, June 2-6, 1980.

[11] Ahern, F. J., D. G. Guodenouah, A. L. Grey, R. A. Ryerson and R. J. Vilbikaitis, "Simul taneous Microwave and ODtical 
[12] Bradley, G. A. and F. T. Ulaby, "Aircraft Radar Response t:0 Soil Moisture," RSL Technical Report 450-2 (AgRISTARi Rejort SM-KO-04005), University of Kansas Center for Research, Inc., October 1980.

[13] Bush, T. F. and F. T. Ulaby, "Fading Characteristics of Parchromatic Radar Backscatter from Selected Agricultural Targets," IEEE Trans. Geoscience Electronics, GE-13, October 1976, pp. 149-75\%.

[14] Frost, V. C., J. A. Stiles, K. S. Shanmugam and J. C. Holtzman, "A System Model for Imaging Radars," Proc. 5th Int'l. Conf. on Pattern Recognition and Image Processing, Miami, FTorida, December 1980.

[15] Ulaby, F. T., "Vegetation Clutter Model," IEEE Tra.5. on Antennas and Prop., AP-23, No. 4, Ju!y 1980, pp. 538-545.

[16] King, C., "Agricultural Terrain Scatterometer Observations with Emphasis on Soil Moisture Variation," RIL Technical Report 177-44, University of Kansas, Lawrence, Kansas, August 9973.

[17] Bradley, J. V., Distribution-Free Statistical Tests, Prentice-Hail, Englewood Cliffs, few Jersey, T968.

[18] Panter, P. F., Communication System Design, McGraw-Hill, pp. 33-37, 1972 .

ORIGINAL PAGE IS

OF POOF QUALITY 